\title{
Counterion Effects on the Adsorption of Acid Orange 8 from Aqueous Solution onto HDTMA-Modified Nanozeolite from Fly Ash
}

\author{
Denise A. Fungaro", Carina P. Magdalena \\ Nuclear and Energy Research Institute (IPEN - CNEN/SP), São Paulo, Brazil \\ *Corresponding author: dfungaro@ipen.br
}

Copyright (C) 2014 Horizon Research Publishing All rights reserved.

\begin{abstract}
Surfactant-modified nanozeolites from coal fly ash were used for the removal of Acid Orange 8 (AO8) from water. The zeolitic material was modified by two cationic surfactants i. e., hexadecyltrimethyl ammonium bromide (HDTMA-Br) and hexadecyltrimethyl ammonium chloride (HDTMA-Cl). Both the modified nanozeolites were characterized using various techniques to obtain its physical and chemical constituents. The adsorbents before and after adsorption were characterized by X-ray diffraction (XRD). The dynamical data obtained at different concentrations for the two organozeolites fit well with pseudo-second-order kinetic model. The equilibrium adsorption data were interpreted in terms of the Langmuir, Freundlich, Temkin, and Dubinin-Radushkevich isotherm models. The results showed that the adsorption of AO8 was influenced by HDTMA-zeolite counterion. Zeolite modified with HDTMA-Br was most efficient than zeolite modified with HDTMA-Cl for AO8 removal. Negative values of Gibbs free energy change $\left(\Delta G^{o}\right)$ for dye adsorption onto HDTMA-modified zeolites indicates that the adsorption process is spontaneous and thermodynamically favorable. As a result, surfactant-modified nanozeolites from coal fly ash could be used as effective adsorbents for AO8 removal from wastewater.
\end{abstract}

Keywords Coal Fly Ash, Zeolite, Adsorption, HDTMA Surfactant, Acid Orange 8

\section{Introduction}

Dyestuff industries and textile industries are, respectively, the largest producers and users of dyes, producing tons of residues which are released into the environment causing serious problems. Among the synthetic dyes released in effluents, azo dyes is one of the more detrimental classes because it is highly persistent in the aquatic environment, due to its chemical compositions, involving aromatic rings, azoic linkages and amino groups[1-2].

Dye removal is complicated by the structural diversity of dyes that may be used in a single dyeing operation, and also by other wastewater constituents that may attenuate the treatment process. A conventional treatment plant, generally consisting of coagulation-flocculation, activated sludge process and chlorination, is clearly incapable of treating dye wastewaters [3-4].

The recent trend in dye wastewater treatment is focused around integration of multiple techniques and adsorption may be included at the end of dye treatment processes as a fail-safe mechanism.

Zeolites synthesized from Brazilian fly ash have been used as low cost adsorbent for dye removal [5-7]. Because the surface of zeolites is negatively charged and hydrophilic in nature, little affinity toward organic pollutants such as anionic dyes is thus expected. Nevertheless, researchers found that permanent negative charges in crystal structures enable zeolites to be modified by cationic surfactants so that they better retain organic pollutants. The surfactants that are commonly employed in the previous studies in attaching onto the surface of zeolite are hexadecyltrimethylammonium (HDTMA). These quaternary amines are composed of a hydrophilic and positively charged head group and a hydrophobic tail in their molecule structures [8-10].

Acid Orange 8 (AO8) is an anionic dye, characterized by the presence of one azo group $(-\mathrm{N}=\mathrm{N}-)$, which is used in larger quantities for cheap articles and, consequently, are abundant in wastewater. Its principal application is in leather, wool dyeing and paper coloration [11-12]. Previous studies have reported the removal of cationic and reactive from water [13-14]. However, to our knowledge, the studies of the adsorption of acid dyes are very limited.

In view of the environmental significance, the main goal of this study was to evaluate the effect of counterions on the adsorbing characteristics of surface surfactant-modified nanozeolite from fly ash. The kinetics and isotherms for AO8 adsorption onto HTMA-modified nanozeolites from fly ash were studied to estimate important capacity and rate 
parameters which can aid in system design.

\section{Materials and Methods}

All the reagents used for experimental studies were of analytical grade. The samples of coal fly ash from baghouse filter were obtained from a coal-fired power plant located at Figueira County, in Paraná State, Brazil. The quaternary ammonium salts hexadecyltrimethylammonium bromide and hexadecyltrimethylammonium chloride (HDTMA-Br and HDTMA-Cl, Merck) were used. The Acid Orange 8 dye (AO8; CI 15575; $\mathrm{C}_{17} \mathrm{H}_{13} \mathrm{~N}_{2} \mathrm{NaO}_{4} \mathrm{~S} ; 364.35 \mathrm{~g} \mathrm{~mol}^{-1}$ ) provided by Aldrich with a dye content of $65 \%$ and was used without further purification. The chemical structure of AO8 is shown in Figure 1. Stock solutions of AO8 were prepared by dissolving the appropriate amounts in doubly distilled water and the solutions for adsorption tests were prepared by diluting it. Concentrations of the aqueous solutions of dye were monitored on UV/Visible spectrophotometer (Varian model Cary 1E).

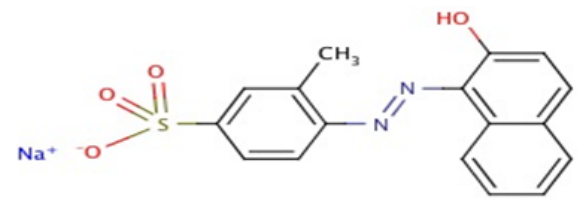

Figure 1. The chemical structure of Acid Orange 8

\subsection{Synthesis of Surfactant-Modified Zeolite from Fly Ash (SMZ)}

Zeolite was prepared by conventional alkaline hydrothermal treatment of coal fly ash (CFA). The main components of raw fly ash are $\mathrm{SiO}_{2}$ and $\mathrm{Al}_{2} \mathrm{O}_{3}$, which are known to be the main components of zeolite; $31 \%$ and $15 \%$, respectively. CFA ( $30 \mathrm{~g})$ was mixed with $240 \mathrm{~mL}$ of $3.5 \mathrm{~mol}$ $\mathrm{L}^{-1}$ aqueous $\mathrm{NaOH}$ solution in a $300 \mathrm{~mL}$ Teflon vessel. This mixture was heated to $100{ }^{\circ} \mathrm{C}$ in oven for $24 \mathrm{~h}$. After finishing of the process, the suspension was filtered with $4 \mathrm{~A}$ quantitative filter paper. The solid zeolite from fly ash product was repeatedly washed with doubly distilled water until the $\mathrm{pH}$ of washing water reach $\sim 11$ and dried at $50{ }^{\circ} \mathrm{C}$ for $12 \mathrm{~h}$ [15]. Zeolites modified with surfactant were prepared by mixing $20 \mathrm{~g}$ of zeolite from fly ash with $400 \mathrm{~mL}$ of $1.8 \mathrm{mmol} \mathrm{L}^{-1}$ HDTMA-Br or HDTMA-Cl. The mixtures were shaken in a mechanical shaker for $7 \mathrm{~h}$ at $120 \mathrm{rpm}$ and $25{ }^{\circ} \mathrm{C}$. After this period, the solid was filtered and taken to the stove for drying at $50{ }^{\circ} \mathrm{C}$ for $12 \mathrm{~h}$ [16]. Unmodified zeolite and zeolites modified with HDTMA-Br and HDTMA-Cl solutions were named as UMZ, SMZ-Br and SMZ-Cl, respectively.

\subsection{Adsorption Studies}

Aliquots of $10 \mathrm{~mL}$ of $\mathrm{AO} 8$ with initial concentrations in the range from 10 to $85 \mathrm{mg} \mathrm{L}^{-1}$ were placed in beakers with
$0.2 \mathrm{~g}$ of zeolitic materials. The suspensions were shaken at $120 \mathrm{rpm}$ at intervals of $5-180 \mathrm{~min}\left(25 \pm 2{ }^{\circ} \mathrm{C}\right)$. The supernatant was separated by centrifugation for $30 \mathrm{~min}$ at $2000 \mathrm{rpm}$. An aliquot of the supernatant was analyzed using a UV spectrophotometer by measuring absorbance at $491 \mathrm{~nm}$, the maximum of absorption peak of $\mathrm{AO}$, and $\mathrm{pH} 5$. Adsorption isotherms were carried out by contacting $0.2 \mathrm{~g}$ of SMZ with $10 \mathrm{~mL}$ of the dye solution of varying initial dye concentrations (24 to $283 \mathrm{mg} \mathrm{L}^{-1}$ for SMZ-Br and 10 to 97 $\mathrm{mg} \mathrm{L}^{-1}$ for SMZ-Cl). The samples were stirred at $120 \mathrm{rpm}$ until they reach equilibrium time under constant temperature of $25 \pm 2{ }^{\circ} \mathrm{C}$. Each experiment was conducted in triplicate under identical conditions to confirm the results, and was found reproducible (experimental error within 5\%).

The amount of the dye uptake and percentage of dye removal by the adsorbent were calculated by applying Eqs. (1) and (2), respectively:

$$
\begin{aligned}
q_{t} & =\frac{(C o-C t) V}{M} \\
R(\%) & =\frac{(C o-C t)}{C o} \times 100
\end{aligned}
$$

where $\mathrm{q}_{\mathrm{t}}$ is the adsorbed amount of adsorbate per gram of adsorbent at any time $\mathrm{t}\left(\mathrm{mg} \mathrm{g}^{-1}\right)$, Co and $\mathrm{Ct}$ the concentrations of the adsorbate in the initial solution and at any time $\mathrm{t}$, respectively $\left(\mathrm{mg} \mathrm{L}^{-1}\right)$; $\mathrm{V}$ the volume of the adsorbate solution added (L) and $\mathrm{M}$ the amount of the adsorbent used (g).

In order to investigate the mechanism of adsorption, characteristic constants were determined using the linearized form of pseudo-first order (3) and pseudo-second order (4) kinetic models with equations as follows:

$$
\begin{gathered}
\log (q e-q t)=\log q e-\frac{k_{1} t}{2.303} \\
\frac{t}{q t}=\frac{1}{k_{2} q e^{2}}-\frac{1}{q e} t
\end{gathered}
$$

where $q_{e}$ is the amount of dye adsorbed at equilibrium (mg $\left.\mathrm{g}^{-1}\right), q t$ is the amount of dye adsorbed at time $t\left(\mathrm{mg} \mathrm{g}^{-1}\right), k_{l}$ is the rate constant of the pseudo-first-order adsorption $\left(\min ^{-1}\right)$, and $k_{2}$ is the rate constant of the pseudo-second-order kinetics $\left(\mathrm{g} \mathrm{mg}^{-1} \mathrm{~min}^{-1}\right)$ [17-19]. The values of $k_{l}$ and $q_{e}$ were obtained from the slope and intercept respectively of plot of $\log \left(q_{e}-q t\right)$ versus $t$ for pseudo- first order model. The values of $q_{e}$ and $k_{2}$ can be determined from the slope and intercept of a plot of $t / q t$ versus $t$, respectively for pseudo-second-order model.

The initial adsorption rate, $\mathrm{h}\left(\mathrm{mg} \mathrm{g}^{-1} \min ^{-1}\right)$, as $\mathrm{t} \rightarrow 0$ can be defined as (5):

$$
h=k_{2} q_{e}^{2}
$$

where $k_{2}$ is the rate constant of the pseudo-second order kinetics $\left(\mathrm{g} \mathrm{mg}^{-1} \mathrm{~min}^{-1}\right)$ and $q_{e}$ is the maximum adsorption capacity $\left(\mathrm{mg} \mathrm{g}^{-1}\right)$.

The kinetic results were analyzed by the intraparticle diffusion model to elucidate the diffusion mechanism, 
which model is expressed as [20]:

$$
q t=k_{i d} t^{0.5}+C
$$

where $k_{\mathrm{id}}$ is the intraparticle diffusion rate constant $\left(\mathrm{mg} \mathrm{g}^{-1}\right.$ $\min ^{-0.5}$ ). According to Equation (6), a plot of $q t$ versus $t^{0.5}$ should be a straight line with a slope $k_{\text {id }}$ and intercept $C$ when adsorption mechanism follows the intraparticular diffusion process.

The data of the isotherm adsorption equilibrium were fitted using the Langmuir, Freundlich, Temkin and Dubinin-Radushkevich (D-R). The mathematical expression of isotherm models (linear and non-linear form) and their parameters have been reported in the literature [5-7, 21-22]. In assessing the fit using linear analysis, the correlation coefficients $(\mathrm{R})$ are compared. The model that best fits the experimental data presents value of $\mathrm{R}$ higher and closer to one. Besides the value of $\mathrm{R}$, six error functions were employed for error analysis, with the lowest values will be used to further validate the applicability of isotherms tested. The equations used (abbreviated as ARED, SSE, MPSED, HYBRID, SAE and $\mathrm{X}^{2}$ ) are described in Table 1 [22].

Table 1. Error functions

\begin{tabular}{|c|c|}
\hline Error Function & Equations \\
\hline $\begin{array}{c}\text { Average relative error } \\
\text { (ARED) }\end{array}$ & $A R E D=\frac{1}{N} \sum\left|\frac{\left(q_{\text {eexp }}-q_{\text {ecal }}\right)}{q_{\text {eexp }}}\right| x 100$ \\
\hline $\begin{array}{c}\text { Sum of the squares of the } \\
\text { errors(SSE) }\end{array}$ & $S S E=\sum\left(q_{\text {ecal }}-q_{\text {eexp }}\right)^{2}$ \\
\hline $\begin{array}{c}\text { Marquardt's percent } \\
\text { standard deviation } \\
\text { (MPSED) }\end{array}$ & $=100 \sqrt{\frac{1}{N-P} \sum\left|\frac{\left(q_{\text {eexp }}-q_{\text {ecal }}\right)^{2}}{q_{\text {eexp }}}\right|} \mid$ \\
\hline $\begin{array}{c}\text { Hybrid fractional error } \\
\text { function (HYBRID) }\end{array}$ & $\begin{array}{c}H Y B R I D \\
N-P \sum\left|\frac{\left(q_{\text {eexp }}-q_{\text {ecal }}\right)^{2}}{q_{\text {eexp }}}\right| x 100\end{array}$ \\
\hline $\begin{array}{c}\text { Sum of the absolute } \\
\text { errors(SAE) }\end{array}$ & $S A E=\sum\left|q_{\text {ecal }}-q_{\text {eexp }}\right|$ \\
\hline Chi-square (X') & $X^{2}=\sum \frac{\left(q_{\text {eexp }}-q_{\text {ecal }}\right)^{2}}{q_{\text {ecal }}}$ \\
\hline
\end{tabular}

\subsection{Characterization of Materials}

Chemical composition of materials was determined by X-ray fluorescence (XRF) in a Rigaku RIX-3000 equipment. $\mathrm{X}$-ray diffraction (XRD) with an automated Rigaku MiniFlex II diffractometer using $\mathrm{CuK} \alpha$ radiation $(\lambda=1.5405 \AA)$ was used to identify the main crystalline compounds. The crystalline phases present in the samples were identified with the help of ICDD (International Centre for Diffraction Data). Bulk density was determined by helium pycnometer (Micromeritics - Accupyc 1330). The surface area was determined by $\mathrm{N}_{2}$ adsorption isotherm with relationship using NOVA 1200 (Quantachrome Corp.). Before adsorption experiments, the samples were degassed at $150{ }^{\circ} \mathrm{C}$ for $12 \mathrm{~h}$. The specific surface area was obtained by five points at $p / p^{\circ}$ between 0.05 and 0.20 applying the Brunauer-Emmet-Teller equation to the adsorption data. The cation exchange capacity (CEC) and external cation exchange capacity (ECEC) were determined by adopting literature techniques $[9,23]$.

The $\mathrm{pH}$ of zeolite was measured as follows: $0.1 \mathrm{~g}$ of samples were mixed with $10 \mathrm{ml}$ of distilled water and shaken for $24 \mathrm{~h}$. After filtration, the $\mathrm{pH}$ of solution was determined by a $\mathrm{pH}$ meter. The point of zero charge $\left(\mathrm{pH}_{\mathrm{PZC}}\right)$ was estimated by using batch equilibrium techniques. For this, $0.1 \mathrm{~g}$ of each adsorbent was treated with $50 \mathrm{~mL}$ of $0.1 \mathrm{~mol} \mathrm{~L}^{-1}$ $\mathrm{NaNO}_{3}$ solution which was used as an inert electrolyte. The initial $\mathrm{pH}$ values $\left(\mathrm{pH}_{\text {initial }}\right)$ were adjusted in the range 2 to 13 by adding minimum amounts of $0.01 \mathrm{~mol} \mathrm{~L}^{-1} \mathrm{NaOH}$ or 0.01 mol L-1 $\mathrm{HNO}_{3}$. The suspensions were allowed to equilibrate for $24 \mathrm{~h}$ in a shaker fixed at $120 \mathrm{rpm}$. After completion of the equilibration time, the admixtures were filtered and final $\mathrm{pH}$ values $\left(\mathrm{pH}_{\text {final }}\right)$ of the filtrates were measured again. A plot of the final $\mathrm{pH}$ as a function of the initial $\mathrm{pH}$ provides $\mathrm{pH}_{\mathrm{pzc}}$ of the adsorbent by the plateau of constant $\mathrm{pH}$ to the ordinate.

\subsection{Results and Discussion}

\subsubsection{AO8 Adsorption Tests}

The experimental results of preliminary AO8 adsorption tests using unmodified zeolite (UMZ) and surfactant modified zeolites (SMZs) materials carried out at $2 \mathrm{~h}$ with solution concentration of $25 \mathrm{mg} \mathrm{L}^{-1}$ are summarized in Table 2. The adsorption capacity of AO8 by unmodified zeolitic material was negligible, but it was augmented greatly by loading with HDTMA-Br and HDTMA-Cl. According to the experimental results, $\mathrm{SMZ}-\mathrm{Br}$ and $\mathrm{SMZ}-\mathrm{Cl}$ shown high AO8 adsorption capacity to be used in remaining experiments. The low adsorption efficiency of anionic reactive dye onto zeolite from fly has been reported [24-25].

Table 2. AO8 percent removal by various adsorbents

\begin{tabular}{|c|c|c|}
\hline Adsorbent & $\begin{array}{c}\text { Type } \\
\text { of surfactant }\end{array}$ & Removal (\%) \\
\hline SMZ-Br & HDTMA-Br & 95 \\
\hline SMZ-Cl & HDTMA-Cl & 65 \\
\hline $\mathrm{UMZ}$ & - & 6.2 \\
\hline
\end{tabular}

\subsubsection{Characterization of Materials}

The chemical composition of the zeolite/untreated and surfactant-modified forms of zeolitic materials is presented in Table 3. The resulting $\mathrm{Al} / \mathrm{Si}$ ratio of the modified zeolites is 0.739 which is fairly close to that of the untreated form (0.727). This indicates that the $\mathrm{Al}$ atoms were not lost into the aqueous media during modification with HDTMA chloride and bromide [26]. The presence of bromide and chloride in the SMZs was detected.

The physicochemical properties of adsorbents are summarized in Table 4. It can be observed that the modified zeolites have lower total BET surface area than the unmodified zeolite (UMZ). Total BET surface area is the summation of external surface area and micropore surface area. When the adsorption of cationic surfactants takes 
place at the external surface and at pore openings (supercages), the internal area of the zeolites is blocked and the micropore surface area decreases. The CEC was determined in the original and in all samples obtained after treating it with HDTMA. It was found $2.00 \mathrm{meq} \mathrm{g}^{-1}$ for UMZ and this exchange capacity was not affected by the presence of the surfactants in the sample because the sites occupied by the surfactants are not considered in the determination.

Table 3. Bulk elemental composition of zeolitic materials samples (concentration percent) done by X-ray fluorescence analysis

\begin{tabular}{|c|c|c|c|}
\hline Oxides & UMZ & SMZ-Cl & SMZ-Br \\
\hline $\mathrm{SiO}_{2}$ & 22 & 23 & 23 \\
\hline $\mathrm{Al}_{2} \mathrm{O}_{3}$ & 16 & 17 & 17 \\
\hline $\mathrm{Fe}_{2} \mathrm{O}_{3}$ & 7.6 & 7.6 & 7.7 \\
\hline $\mathrm{CaO}$ & 3.2 & 3.5 & 3.4 \\
\hline $\mathrm{K}_{2} \mathrm{O}$ & 0.6 & 0.5 & 0.6 \\
\hline $\mathrm{SO}_{3}$ & 1.0 & 1.2 & 1.0 \\
\hline $\mathrm{TiO}_{2}$ & 1.2 & 1.2 & 1.2 \\
\hline $\mathrm{MgO}$ & 1.2 & 1.2 & 1.2 \\
\hline $\mathrm{Na}_{2} \mathrm{O}$ & 6,3 & 7.3 & 6.1 \\
\hline $\mathrm{ZnO}$ & 0.21 & 0.20 & 0.22 \\
\hline $\mathrm{MnO}$ & 0.08 & 0.09 & 0.13 \\
\hline $\mathrm{PbO}$ & 0.07 & 0.06 & 0.06 \\
\hline $\mathrm{Br}$ & $<0.02$ & $<0.02$ & 0.04 \\
\hline $\mathrm{Cl}$ & $<0.02$ & 0.07 & $<0.02$ \\
\hline $\mathrm{Cr}_{2} \mathrm{O}_{3}$ & 0.02 & 0.03 & 0.03 \\
\hline $\mathrm{ZrO}_{2}$ & 0.03 & 0.03 & 0.03 \\
\hline $\mathrm{U}_{3} \mathrm{O}_{8}$ & 0.03 & 0.03 & 0.03 \\
\hline $\mathrm{NiO}$ & 0.02 & 0.02 & 0.02 \\
\hline others & $<0.02$ & $<0.02$ & $<0.02$ \\
\hline
\end{tabular}

The external cation exchange capacity (ECEC) of UMZ accounts for $24 \%$ of CEC. The external surface was used to load HDTMA-Br and HDTMA-Cl because the pore size of zeolite is too small for the HDTMA cation to enter.

The unmodified zeolite from fly ash has a point of zero charge (pHpzc) of 8 and is negatively charged. The point of zero charge of the surfactant modified zeolites was found to be 7.0 and the particle surface was still negative for both materials. SMZs have negative charge probably due to the formation of a patchy mono-layer and/or bi-layers form on the external zeolite surface [27-30]. The physicochemical properties of the resultant SMZs were not affected by the HDTMA counterion.

The diffraction patterns obtained, before and after adsorption of AO8 onto SMZ-Br and SMZ-Cl, are shown in Figures 2 and 3, respectively. Formation of zeolite via conventional alkali hydrothermal reaction of coal fly ash was confirmed by XRD patterns. Hydroxysodalite (JCPDS
31-1271) can be identified as the dominant zeolite phase in both surfactant-modified zeolitic materials.

Table 4. Physicochemical properties of unmodified zeolite (UMZ) and surfactant-modified zeolites (SMZ)

\begin{tabular}{|c|c|c|c|}
\hline Characteristics & UMZ & SMZ-Br & SMZ-Cl \\
\hline BET surface area $\left(\mathrm{m}^{2} \mathrm{~g}^{-1}\right)$ & 73.4 & 66.4 & 66.4 \\
\hline Bulk density $\left(\mathrm{g} \mathrm{cm}^{-3}\right)$ & 2.51 & 2.47 & 2.44 \\
\hline $\mathrm{pH}$ in water & 9.2 & 9.1 & 9.4 \\
\hline $\mathrm{pH}_{\mathrm{PZC}}{ }^{\mathrm{a}}$ & 8.0 & 7.0 & 7.0 \\
\hline $\mathrm{CEC}\left(\mathrm{meq} \mathrm{g}^{-1}\right)^{\mathrm{b}}$ & 2.00 & 2.06 & 1.84 \\
\hline ECEC $\left(\mathrm{meq} \mathrm{g}^{-1}\right)^{\mathrm{c}}$ & 0.475 & - & - \\
\hline
\end{tabular}

(a) point of zero charge;(b) cation exchange capacity;(c) external cation exchange capacity

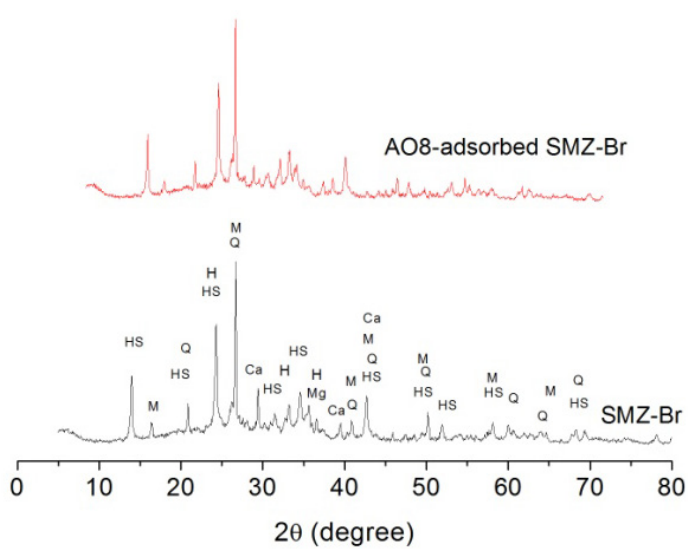

Figure 2. XRD patterns of SMZ-Br and AO8-adsorbed $\mathrm{SMZ}-\mathrm{Br}(\mathrm{M}=$ Mulitte; $\mathrm{Q}=$ Quartz; $\mathrm{Mg}=$ Magnetite; $\mathrm{H}=$ Hematite; $\mathrm{Ca}=$ Calcite; $\mathrm{HS}=$ Hydroxysodalite)

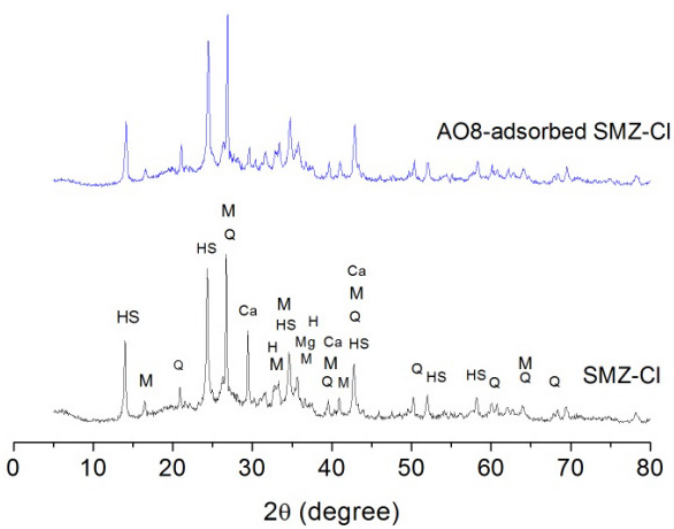

Figure 3. XRD patterns of $\mathrm{SMZ}-\mathrm{Br}$ and $\mathrm{AO}$-adsorbed $\mathrm{SMZ}-\mathrm{Cl}(\mathrm{M}=$ Mulitte; $\mathrm{Q}=$ Quartz; $\mathrm{Mg}=$ Magnetite; $\mathrm{H}=$ Hematite; $\mathrm{Ca}=$ Calcite; $\mathrm{HS}=$ Hydroxysodalite)

According to the obtained results and the XRD data, the oxide formula $\mathrm{Na}_{1.08} \mathrm{Al}_{2} \mathrm{Si}_{1.68} \mathrm{O}_{7.44} .1 .8 \mathrm{H}_{2} \mathrm{O}$ fits best for the synthesized hydroxysodalite. This type of hydroxysodalite was obtained after fly ash activation using the same synthesis conditions [31-32].

The XRD pattern confirmed that quartz (JCPDS 85-0796), 
mullite (JCPDS 74-4143), Fe-material (Magnetite, ICDD/JCPDS 89-0691; Hematite, ICDD/JCPDS 89-0598) and Calcite $\left(\mathrm{CaCO}_{3}, \mathrm{ICDD} / \mathrm{JCPDS}\right.$ 01-071-3699) are also present in the obtained zeolitic materials, and that generally they were not involved in the conversion process of fly ash under the given experimental conditions.

It is important to note that no diffraction peaks, due to the HDTMA-Br and HDTMA-Cl in the samples treated with it, were observed. Previous studies showed that the surfactant conditioning has no effects on the structure of the zeolitic material from fly ash [16].

It is evident from the Figures 2 and 3 that there is no appreciable change in the spectra of adsorbents after AO8 adsorption. This may be due to the fact that adsorption does not alter the chemical nature of the surface of the surfactant modified zeolites.

\subsubsection{AO8 Adsorption Kinetics}

The effect on initial concentration of AO8 adsorption onto SMZ-Br and SMZ-Cl are presented in Figs. 4-5, respectively. A rapid increased is observed for the first $20 \mathrm{~min}$ and it then proceeds slowly until reached equilibrium. This may due to the increased in the number of vacant surface sites available at initial stage. The adsorption equilibrium was reached at 40 min for SMZ-Br and 60 min for SMZ-Cl.

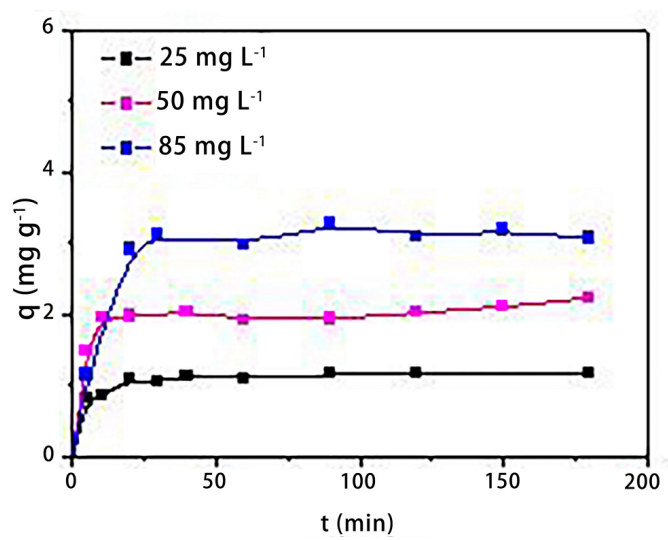

Figure 4. Effect of contact time and initial concentration on the adsorption of AO8 on SMZ-Br

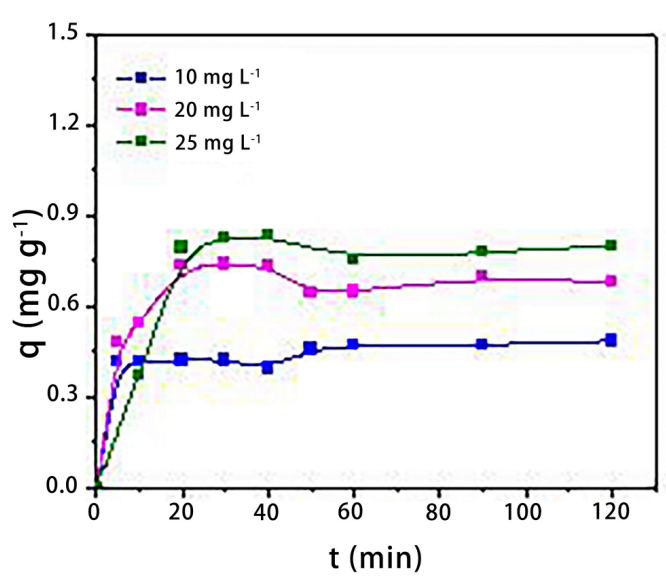

Figure 5. Effect of contact time and initial concentration on the adsorption of $\mathrm{AO} 8$ on $\mathrm{SMZ}-\mathrm{Cl}$
The equilibrium adsorption is increased from 1.13 to 3.20 $\mathrm{mg} \mathrm{\textrm {g } ^ { - 1 }}$ and percentage removal is decreased from 93.0 to $77.1 \%$ for system $\mathrm{AO} 8 / \mathrm{SMZ}-\mathrm{Br}$ and increased from 0.49 to $0.80 \mathrm{mg} \mathrm{g}^{-1}$ and percentage removal is decreased from 87.0 to $65.5 \%$ for system $\mathrm{AO} / \mathrm{SMZ}-\mathrm{Cl}$ as initial concentration increased.

The kinetic models considered in this study were the pseudo-first-order, the pseudo-second-order and the intra-particle diffusion. The relevant equations of these models (3-6) were used to identify the kinetic behaviors of the adsorption process and the prevailing mechanisms.

The adsorption kinetic plots are shown in Figures 6-7 for SMZ-Br and SMZ-Cl, respectively and all values of the kinetic constants obtained for adsorption of AO8 onto SMZs are presented in Table 5 and 6.
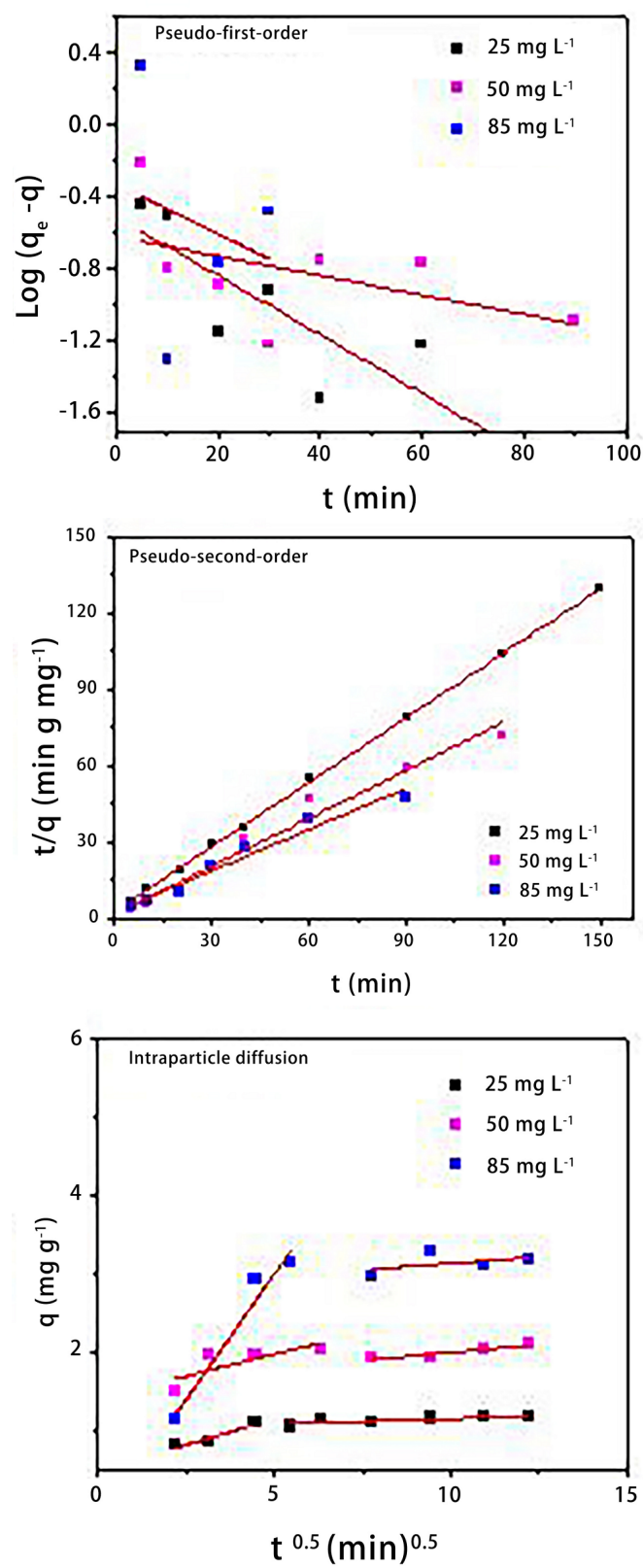

Figure 6. Pseudo-first-order kinetics, pseudo-second-order kinetics and intraparticle diffusion model plots for the adsorption of AO8 on SMZ-Br at various concentrations 
Good correlation coefficients were obtained for the pseudo-second-order kinetic model, which shows that the uptake process follows the pseudo-second-order rate expression with the correlation coefficients being $>0.99$. The experimental adsorption capacity values $\left(\mathrm{q}_{\mathrm{e}} \exp \right)$ were found to be in agreement with those of the theoretical adsorption capacity $\left(\mathrm{q}_{\mathrm{e}}\right.$ calc $)$ that were calculated with the pseudo-second order model for the two modified zeolitic materials.
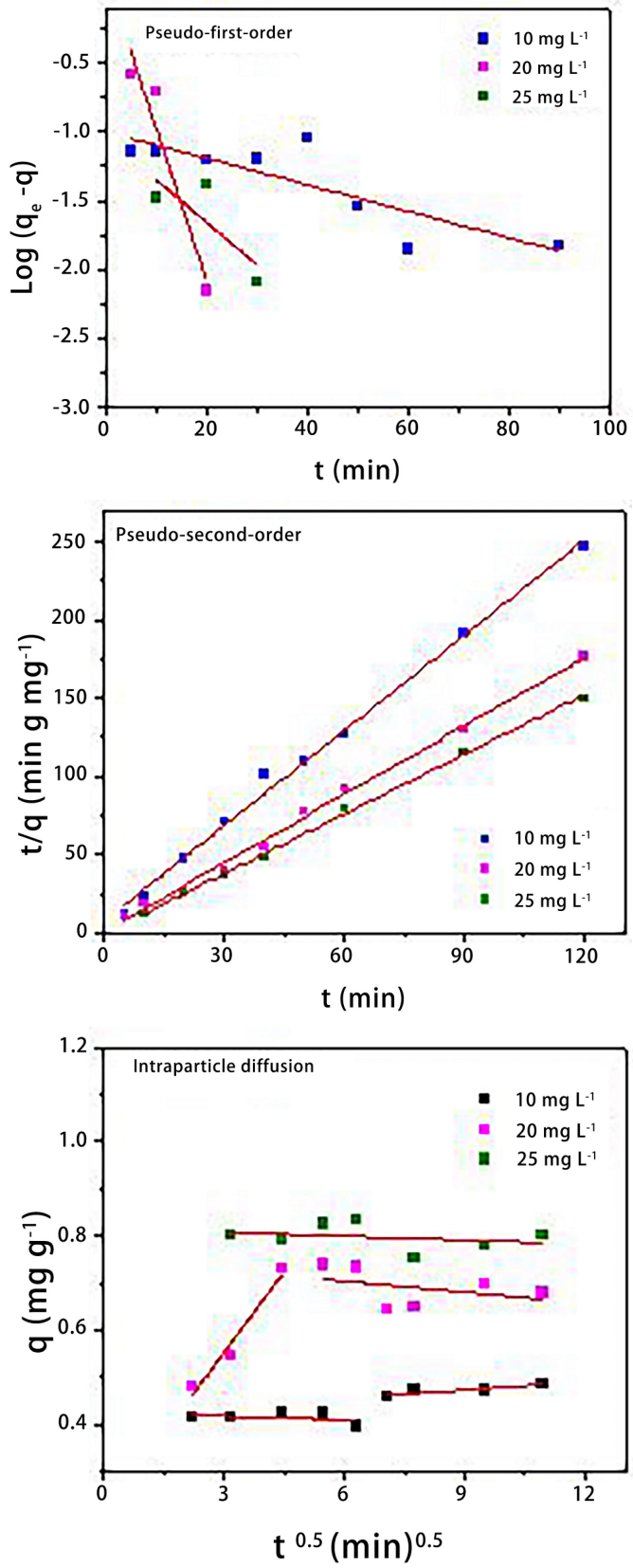

Figure 7. Pseudo-first-order kinetics, pseudo-second-order kinetics and intraparticle diffusion model plots for the adsorption of AO8 on SMZ-Cl at various concentrations

As seen in Table 5 and 6, comparing the $\mathrm{q}_{\mathrm{e}}$ values for each material and same concentration of dye, it may be concluded that AO8 adsorption onto modified zeolite with HDTMA-Br is faster than modified zeolite with HDTMA-Cl.
Table 5. Kinetic parameters for the removal of AO8 by SMZ-Br

\begin{tabular}{|c|c|c|c|c|c|}
\hline $\begin{array}{l}\mathrm{AO} 8 \\
(\mathrm{mg}\end{array}$ & \multicolumn{5}{|c|}{ Pseudo-First Order } \\
\hline & $\begin{array}{c}\mathrm{K}_{1} \\
\left(\mathrm{~g} \mathrm{mg}^{-1} \min ^{-1}\right)\end{array}$ & $\begin{array}{c}\mathrm{q}_{\mathrm{e}} \text { calc } \\
\left(\mathrm{mg} \mathrm{g}^{-1}\right)\end{array}$ & $\begin{array}{c}\mathrm{q}_{\mathrm{e}} \exp \\
\left(\mathrm{mg} \mathrm{g}^{-1}\right)\end{array}$ & $\mathrm{R}_{1}$ & \\
\hline 25 & $3.77 \times 10^{-3}$ & 0.306 & 1.13 & 0.896 & \\
\hline 50 & $7.96 \times 10^{-3}$ & 0.224 & 2.04 & 0.466 & \\
\hline \multirow[t]{3}{*}{85} & $17.8 \times 10^{-3}$ & 0.465 & 3.12 & 0.263 & \\
\hline & \multicolumn{5}{|c|}{ Pseudo-Second Order } \\
\hline & $\begin{array}{c}\mathrm{K}_{2} \\
\left(\mathrm{~g} \mathrm{mg}^{-1} \min ^{-1}\right)\end{array}$ & $\begin{array}{c}\mathrm{h} \\
\left(\mathrm{mg} \mathrm{g}^{-1}\right. \\
\left.\min ^{-1}\right)\end{array}$ & $\begin{array}{l}\mathrm{q}_{\mathrm{e}} \text { calc } \\
\left(\mathrm{mg} \mathrm{g}^{-1}\right)\end{array}$ & $\begin{array}{c}\mathrm{q}_{\mathrm{e}} \exp \\
(\mathrm{mg} \\
\left.\mathrm{g}^{-1}\right) \\
\end{array}$ & $\mathrm{R}_{2}$ \\
\hline 25 & $28.2 \times 10^{-2}$ & $3.91 \times 10^{-1}$ & 1.18 & 1.13 & 0.999 \\
\hline 50 & $22.4 \times 10^{-2}$ & $9.58 \times 10^{-1}$ & 2.07 & 2.04 & 0.998 \\
\hline \multirow[t]{3}{*}{85} & $6.37 \times 10^{-2}$ & $6.94 \times 10^{-1}$ & 3.30 & 3.12 & 0.997 \\
\hline & \multicolumn{5}{|c|}{ Intraparticle Diffusion } \\
\hline & $\begin{array}{c}\mathrm{C} \\
\left(\mathrm{mg} \mathrm{g}^{-1}\right)\end{array}$ & $\begin{array}{c}\mathrm{K}_{\text {dif } 2} \\
\left(\mathrm{mg} \mathrm{g}^{-1}\right. \\
\left.\min ^{0.5}\right) \\
\end{array}$ & $\mathrm{R}_{\mathrm{dif} 2}$ & & \\
\hline 25 & 0.481 & $1.44 \times 10^{-2}$ & 0.819 & & \\
\hline 50 & 1.40 & $4.11 \times 10^{-2}$ & 0.942 & & \\
\hline 85 & 0.213 & $3.33 \times 10^{-2}$ & 0.462 & & \\
\hline
\end{tabular}

Table 6. Kinetic parameters for the removal of AO8 by SMZ-Cl

\begin{tabular}{|c|c|c|c|c|c|}
\hline $\begin{array}{r}\mathrm{AO} 8 \\
(\mathrm{mg}\end{array}$ & \multicolumn{5}{|c|}{ Pseudo-First Order } \\
\hline & $\begin{array}{c}\mathrm{K}_{1} \\
\left(\mathrm{~g} \mathrm{mg}^{-1} \min ^{-1}\right)\end{array}$ & $\begin{array}{c}\mathrm{q}_{\mathrm{e}} \text { calc } \\
\left(\mathrm{mg} \mathrm{g}^{-1}\right)\end{array}$ & $\begin{array}{c}\mathrm{q}_{\mathrm{e}} \exp \\
\left(\mathrm{mg} \mathrm{g}^{-1}\right)\end{array}$ & $\mathrm{R}_{1}$ & \\
\hline 10 & $2.22 \times 10^{-2}$ & 0.100 & 0.472 & 0.838 & \\
\hline 20 & $25.3 \times 10^{-2}$ & 1.35 & 0.649 & 0.966 & \\
\hline \multirow[t]{3}{*}{25} & $7.08 \times 10^{-2}$ & 0.0933 & 0.753 & 0.798 & \\
\hline & \multicolumn{5}{|c|}{ Pseudo-Second Order } \\
\hline & $\begin{array}{c}\mathrm{K}_{2} \\
\left(\mathrm{~g} \mathrm{mg}^{-1} \min ^{-1}\right)\end{array}$ & $\begin{array}{c}\mathrm{h} \\
\left(\mathrm{mg} \mathrm{g}^{-1}\right. \\
\left.\mathrm{min}^{-1}\right) \\
\end{array}$ & $\begin{array}{l}\mathrm{q}_{\mathrm{e}} \text { calc } \\
\left(\mathrm{mg} \mathrm{g}^{-1}\right)\end{array}$ & $\begin{array}{c}\mathrm{q}_{\mathrm{e}} \exp \\
(\mathrm{mg} \\
\left.\mathrm{g}^{-1}\right) \\
\end{array}$ & $\mathrm{R}_{2}$ \\
\hline 10 & $53.4 \times 10^{-2}$ & $13.1 \times 10^{-2}$ & 0.495 & 0.472 & 0.997 \\
\hline 20 & $223 \times 10^{-2}$ & $105 \times 10^{-2}$ & 0.689 & 0.649 & 0.997 \\
\hline \multirow[t]{3}{*}{25} & $450 \times 10^{-2}$ & $282 \times 10^{-2}$ & 0.793 & 0.753 & 0.999 \\
\hline & \multicolumn{5}{|c|}{ Intraparticle Diffusion } \\
\hline & $\begin{array}{c}\mathrm{C} \\
\left(\mathrm{mg} \mathrm{g}^{-1}\right)\end{array}$ & $\begin{array}{c}\mathrm{K}_{\text {dif2 }} \\
\left(\mathrm{mg} \mathrm{g}^{-1}\right. \\
\left.\text { min }^{0.5}\right) \\
\end{array}$ & $\mathrm{R}_{\mathrm{dif2}}$ & & \\
\hline 10 & 0.424 & $6.02 \times 10^{-3}$ & 0.890 & & \\
\hline 20 & 0.208 & $7.68 \times 10^{-3}$ & 0.393 & & \\
\hline 25 & 0.816 & $2.85 \times 10^{-3}$ & 0.291 & & \\
\hline
\end{tabular}

The adsorbate transport from the solution to the surface of the adsorbent occurs in several steps. This phenomenon may be controlled by one or more steps such as film or external diffusion, pore diffusion, surface diffusion and adsorption on the pore surface, or a combination of more than one step 
through the adsorption process. According to the intraparticle diffusion model, if the rate-controlling step is an intraparticle diffusion, a plot of dye adsorbed $(q)$ against square root of contact time $\left(t^{0.5}\right)$ leads to a straight line passing through the origin [20].

In this work, the $\mathrm{C}$ values, obtained from the intercept of the $\mathrm{q}$ versus $\mathrm{t}^{1 / 2}$ plots, indicate that the line did not pass through the origin hence intraparticle diffusion is not the only rate limiting mechanism (Figures 4 and 5). In this case, the adsorption process is complex and more kinetic models that operate simultaneously may control the rate of dye adsorption. From Figures 4 and 5, it may be seen that there are two separate regions. The first part of the curve can be attributed to mass transfer effects taking place with boundary layer diffusion, while the final linear parts indicate intraparticle diffusion (very slow diffusion of the dye from the surface film into the micropores, which are east accessible sites of adsorption) [33]. This behavior is possibly due to the heterogeneous nature of the adsorbents. The absence of such features in the plot for the adsorption of AO8 onto SMZ-Cl with higher concentration (Figure 5) indicated that the steps were indistinguishable from one another in this case.

\subsubsection{Adsorption equilibrium of AO8 on SMZs}

Adsorption isotherm models provide useful data in order to understand the mechanisms of the adsorption process and to evaluate its applicability. The Langmuir, Freundlich, Temkin, and Dubinin-Radushkevich (D-R) isotherm models were used to describe the relationship between the amount of AO8 adsorbed onto the SMZs and their equilibrium concentrations in aqueous solution. The modeled isotherms are plotted in Figures 8 and 9 for SMZ-Br and SMZ-Cl, respectively.

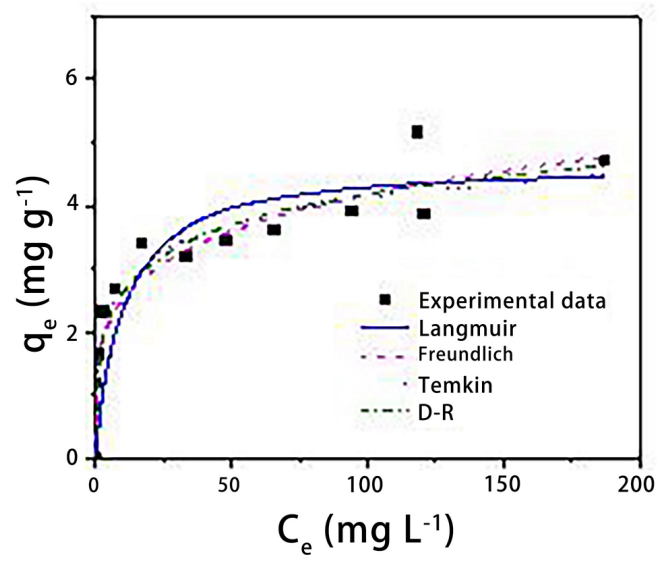

Figure 8. Adsorption isotherms of AO8 by SMZ-Br (adsorbent dose: 0.2 $\mathrm{g} / 10 \mathrm{~mL}$, agitation speed: $120 \mathrm{rpm}, \mathrm{pH}: 5.0$, contact time: $40 \mathrm{~min}$, temperature: $25 \pm 2{ }^{\circ} \mathrm{C}$ )

The shape of the isotherms was classified as an L4 (Langmuir type 4) curve according to the Giles classification [34] for both SMZ-Br and SMZ-Cl. After the first degree of saturation of the surface, the subsequent rise represents the development of a second layer which is completed. The turning point may represent a change in the mode of packing of the adsorbate.

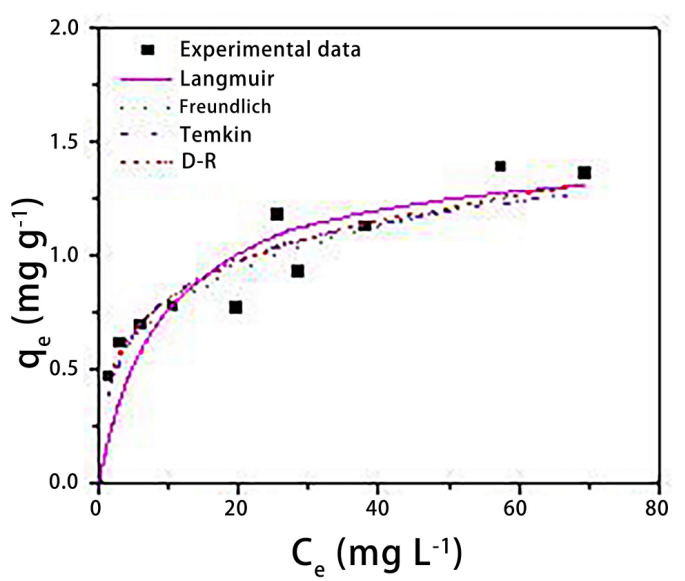

Figure 9. Adsorption isotherms of $\mathrm{AO} 8$ by $\mathrm{SMZ}-\mathrm{Cl}$ (adsorbent dose: 0.2 $\mathrm{g} / 10 \mathrm{~mL}$, agitation speed: $120 \mathrm{rpm}, \mathrm{pH}: 5.0$, contact time: $60 \mathrm{~min}$, temperature: $25 \pm 2{ }^{\circ} \mathrm{C}$ )

The isotherm constants were calculated by evaluating the linearized form of the models. The linear plots of $\mathrm{Ce} / \mathrm{qe}$ versus $\mathrm{Ce}$, log qe versus $\log \mathrm{Ce}$, qe versus $\ln \mathrm{Ce}$ and $\ln$ qe versus $\epsilon^{2}$ were employed to determine the parameters of Langmuir, Freundlich, Temkin, and D-R isotherm models, respectively (figures not shown). All of the isotherm constants and correlation coefficients $(\mathrm{R})$ are given in Table 7. The $R$ values $(>0.9)$ suggest that the four isotherms provide a good model of the adsorption system. In the case of Freundlich model, $\mathrm{n}$ coefficient values were higher than 1, confirming favorable adsorption at high concentrations, but much less favorable at lower concentrations [35].

By evaluating the D-R isotherm model, the mean adsorption energy, E, values were found to be $17.5 \mathrm{~kJ} \mathrm{~mol}^{-1}$ for $\mathrm{SMZ}-\mathrm{Br}$ and $15.5 \mathrm{~kJ} \mathrm{~mol}^{-1}$ for $\mathrm{SMZ}-\mathrm{Cl}$, suggesting that adsorption of AO8 onto SMZs is of chemical nature.

Thermodynamic data such as adsorption energy can be evaluated from Langmuir equation [36]. According to thermodynamic law, $\Delta \mathrm{G}^{\circ}$ of adsorption is calculated as follows:

$$
\Delta \mathrm{G}^{\circ} \mathrm{ads}=-\mathrm{R} \mathrm{T} \ln \mathrm{K}_{\mathrm{L}}
$$

where $\Delta \mathrm{G}^{\circ}$ is free energy of adsorption $\left(\mathrm{kJ} \mathrm{mol}^{-1}\right), \mathrm{T}$ is the absolute temperature $(\mathrm{K}), \mathrm{K}_{\mathrm{L}}$ is the Langmuir equilibrium constant $\left(\mathrm{L} \mathrm{mol}^{-1}\right)$ and $\mathrm{R}$ is the gas constant $\left(8.314 \mathrm{~J} \mathrm{~K}^{-1}\right.$ $\left.\mathrm{mol}^{-1}\right)$.

Using Langmuir isotherm, the free energy value was evaluated as - $26.3 \mathrm{~kJ} \mathrm{~mol}^{-1}$ for both surfactant-modified zeolitic materials. A negative $\Delta \mathrm{G}^{\circ}$ value indicates that adsorption of AO8 from aqueous solution onto SMZs is spontaneous in nature.

Generally, the most widely used approach to determine the isotherm parameters is by linear regression with $\mathrm{R}$ value in the range of 0.9 to 1 being deemed to provide the best fit. This method appears to give an acceptable fit to the experimental data in this study (Table 7). However, due to 
the inherent bias resulting from the linearization of the adsorption isotherm equation, additional six non-linear regression error functions have been considered to further validate the applicability of the tested isotherms [21-22].

Table 7. Isotherm constants for adsorption AO8 o onto modified zeolitic materials

\begin{tabular}{|c|c|c|}
\hline & $\mathrm{SMZ}-\mathrm{Br}$ & $\mathrm{SMZ}-\mathrm{Cl}$ \\
\hline \multicolumn{3}{|c|}{ Langmuir } \\
\hline $\mathrm{Q}_{\mathrm{O}}\left(\mathrm{mg} \mathrm{g}^{-1}\right)$ & 4.67 & 1.48 \\
\hline $\mathrm{b}\left(\mathrm{L} \mathrm{mg}^{-1}\right)$ & 0.115 & 0.114 \\
\hline $\mathrm{R}$ & 0.984 & 0.974 \\
\hline \multicolumn{3}{|c|}{ Freundlich } \\
\hline $\mathrm{K}_{\mathrm{f}}\left(\mathrm{mg} \mathrm{g}^{-1}\right)\left(\mathrm{L} \mathrm{mg}^{-1}\right)^{1 / n}$ & 1.56 & 0.424 \\
\hline $\mathrm{n}$ & 4.67 & 3.73 \\
\hline $\mathrm{R}$ & 0.966 & 0.959 \\
\hline \multicolumn{3}{|c|}{ Temkin } \\
\hline $\mathrm{Kt}\left(\mathrm{L} \mathrm{g}^{-1}\right)$ & 13.87 & 3.74 \\
\hline $\mathrm{B}_{\mathrm{t}}$ & 0.570 & 0.230 \\
\hline $\mathrm{Bt}\left(\mathrm{kJ} \mathrm{mol}^{-1}\right)$ & 4.34 & 10.7 \\
\hline $\mathrm{R}$ & 0.947 & 0.926 \\
\hline \multicolumn{3}{|c|}{$\mathrm{D}-\mathrm{R}$} \\
\hline$\beta\left(\mathrm{mol}^{2} \mathrm{~J}^{-2}\right)$ & $1.68 \times 10^{-9}$ & $2.07 \times 10^{-9}$ \\
\hline $\operatorname{Kdr}\left(\mathrm{mol} \mathrm{g}^{-1}\right)$ & $23 \times 10^{-6}$ & $9.16 \times 10^{-6}$ \\
\hline $\mathrm{E}\left(\mathrm{kJ} \mathrm{mol}^{-1}\right)$ & 17.2 & 15.5 \\
\hline $\mathrm{R}$ & 0.972 & 0.953 \\
\hline
\end{tabular}

The values of error analysis for Langmuir, Freundlich, Temkin and D-R isotherm models are presented in Table 8. Following the conventional approach of determination of the isotherm parameters by linear regression and judging the best fit isotherm from the $\mathrm{R}$ values (Table 7) suggested that the Langmuir isotherm provided a reasonable description and analysis of the experimental data for both surfactant modified-zeolites. However, it can be concluded based on the error values that the most applicable isotherms to describe AO8 - surfactant modified-zeolite adsorption system are D-R and Freundlich isotherms for SMZ-Br and SMZ-Cl, respectively.

The results indicate that counterions have significant effects on AO8 adsorption on HDTMA-treated zeolite from fly ash. The maximum adsorption (Qo) value calculated from the Langmuir in adsorption of AO8 on SMZ-Br is about three times higher than that adsorbed for SMZ-Cl.

As shown in Table 2, the removal percentage of AO8 was $95 \%$ with SMZ-Br and $65 \%$ onto SMZ-Cl. Thus, to achieve the maximum adsorption capacity of $\mathrm{AO} 8$ on HDTMA-treated zeolite, HDTMA-Br will be more effective than HDTMA-Cl and less HDTMA is required to achieve the same $\mathrm{AO} 8$ adsorption when $\mathrm{Br}^{-}$instead $\mathrm{Cl}^{-}$is the counterion.
Table 8. Error functions analysis related to the adsorption of AO8 onto surfactant modified-zeolites

\begin{tabular}{|c|c|c|c|c|c|c|c|}
\hline & ARED & SSE & MPSED & HYBRID & SAE & $X^{2}$ \\
\hline \multicolumn{7}{|c|}{ SMZ-Br } \\
\hline Langmuir & 19.3 & 117 & 49.8 & 112 & 34 & 205 \\
\hline Freundlich & 26 & 46.4 & 53 & 57.7 & 21 & 7.94 \\
\hline Temkin & 59.3 & 146 & 104 & 257 & 42.8 & 5.70 \\
\hline D-R & 33.2 & 76.7 & 61.1 & 80.1 & 30.2 & 10.3 \\
\hline \multicolumn{7}{|c|}{ SMZ-Cl } \\
\hline Langmuir & 27.3 & 153 & 387 & 192 & 28.6 & 329 \\
\hline Freundlich & 9.24 & 24.2 & 11.8 & 19.3 & 13.6 & 1.61 \\
\hline Temkin & 6.33 & 17.5 & 8.41 & 12.2 & 10.9 & 0.930 \\
\hline D-R & 6.93 & 18.8 & 9.12 & 13.7 & 11.5 & 1.06 \\
\hline
\end{tabular}

According to the literature, the critical micelle concentration (CMC) is $0.9 \mathrm{mmol} \mathrm{L}^{-1}$ and $1.25 \mathrm{mmol} \mathrm{L}^{-1}$ at $25^{\circ} \mathrm{C}$ for HDTMA-Br and HDTMA-Cl, respectively [10].

The higher the CMC, the larger the ratio between the monomers and the micelles at a given solution concentration and the lower the probability of monomers associating to form micelles in solution or admicelles on the surface. Therefore, it may be concluded that, when $\mathrm{Cl}^{-}$is the counterion, the ratio of bilayer to monolayer will be smaller than the ratio when $\mathrm{Br}^{-}$is the counterion. Because of the smaller micelle aggregates, a lower adsorption capacity of the surfactant layer will result for $\mathrm{AO} 8$ on HDTMA-Cl-modified zeolite.

On the other hand, it was found that the chromate adsorption maxima for HDTMA-Cl-modified zeolite was higher than for HDTMA-Br-modified zeolite. The adsorption of oxyanion by cationic HDTMA-modified zeolite was attributed to anion exchange on exposed surfactant headgroups resulting from formation of a surfactant bilayer. The process involves the replacement of weakly held counterions by strongly held counterions. The ability of chromate to replace $\mathrm{Cl}^{-}$was greater than that of chromate to replace $\mathrm{Br}^{-}$because $\mathrm{Cl}^{-}$is less closely bound to the HDTMA micelle than $\mathrm{Br}^{-}[10,37]$.

Thus, as HDTMA-Br-modified zeolite showed the greatest removal efficiency, partitioning process is suggested to be predominant mechanisms in AO8 adsorption by SMZs among other possible mechanisms.

The roles that the counterions play in stabilizing an adsorbed surfactant bilayer can be compared to the roles they play in stabilizing micelles in solution. Counterions stabilize ionic surfactant micelles by binding to the micelle surface and screening the electrostatic repulsions between the ionic headgroups. In this way, the counterion binding affinity influences the bulk self-assembly process $[10,38]$.

Adsorption of Acid Orange 8 onto HDTMA-Br-modified clinoptilolite was studied conducting batch experiment system [39]. The value of the maximum adsorption capacity determined from the Langmuir isotherm was $44.05 \mathrm{mg} \mathrm{g}^{-1}$. 
The high adsorption capacity value obtained was due the effect of surfactant concentration on the adsorptive properties of SMZs. Increasing the surfactant loading on the zeolites resulted in an increase in removal of organic pollutants [40-41].

\section{Conclusion}

The main drawback of coal-fired power plants in Brazil is the high production of ash. The generation rate of coal fly ash is approximately 4 million tons per year and is predicted to increase.

Great part of this fly ash is applied as raw material for cement and concrete production $(\sim 30 \%$ of the total), while a small part is used in road-stabilizer. The remaining solid wastes are disposed in on-site ponds, nearby abandoned or active mine sites, or landfills. The coal ash in the environment is exposed to various influences, and solubilization processes take place, sometimes transforming almost insoluble metals to soluble species, and leading to pollution of water and soil.

Converting fly ash into zeolites not only alleviates the disposal problem but also converts a waste material into a value-added product. The utilization of wastes for the synthesis of valuable commercial products may contribute to the economic development and to prevent environment pollution especially in developing countries.

On the other hand, the production of low-cost adsorbent and their application for dye removal from water are considered valuable components in the implementation of sustainable development policies of national and local programs, and present economic advantages.

Zeolite was synthesized from coal fly ash and was subsequently modified with cationic surfactants (HDTMA-Br and HDTMA-Cl). The prepared surfactant-modified nanozeolitic materials, SMZ-Br and SMZ-Cl, were examined for the removal of Acid Orange 8 (AO8) from aqueous solution. In order to optimise the adsorption-isotherm model, correlation coefficient $(\mathrm{R})$ and six error functions were adopted. By means of the error analysis, equilibrium adsorption data were best represented by the D-R and Freundlich isotherm models for SMZ-Br and SMZ-Cl, respectively. The adsorption process obeyed the pseudo-second-order kinetics well for both materials. AO8 adsorption was influenced by the HDTMA-zeolite counterion. Zeolite modified by HDTMA-Br showed a higher adsorption capacity for $\mathrm{AO} 8$ dye and faster adsorption kinetics than the zeolite modified by HDTM-Cl. This can be attributed to effect of counterions in stabilizing HDTMA bilayer on zeolite surface.

Removal efficiencies until $98 \%$ and $87 \%$ were obtained for both SMZ-Br and SMZ-Cl, respectively. It can be concluded that the surfactant-modified zeolitic materials product from fly ash are an efficient adsorbents for the removal of AO8 from aqueous solution.

It is further suggested that after lab scale batch studies, column and pilot-plant studies should also be conducted utilizing HTMA-modified nanozeolites from fly ash with synthetic and real effluents to check their feasibility on commercial scale. In addition acute toxicity tests conducted with Daphnia magna and Vibrio fischeri with the water obtained after the treatment using surfactant-modified nanozeolitic material must be performed to predict the safety of treated effluent.

\section{Acknowledgement}

The authors are grateful to Comissão Nacional de Energia Nuclear for financial support and Carbonífera do Cambuí (Figueira Power Plant) for fly ash samples.

\section{REFERENCES}

[1] M. Mathur, P. Bratnagar, P. Sharma. Review of Mutagenicity of Textile Dye Products, Universal Journal of Environmental Research and Technology, Vol. 2, 1-18, 2012.

[2] B. C. Ventura-Camargo, M. A. Marin-Morales. Dyes: Characterization and Toxicity- A Review. Textiles and Light Industrial Science and Technology (TLIST) Vol. 2, 85-103, 2013.

[3] R. O. Lima, A. P. Bazo, D. M. F. Salvadorri, M. Rech, D. P. Oliveira, G. A. Umbuzeiro. Mutagenic and carcinogenic potential of a textile azo dye processing plant effluent that impacts a drinking water source, Mutation Research, Vol. 626, 53-60, 2007.

[4] D. P. Oliveira, P. A. Carneiro, M. K. Sakagani, M. V. B. Zanoni and G. A. Umbuzeiro, Chemical characterization of a dye processing plant effluent-identification of the mutation components, Mutation Research, Vol. 626, 135- 142, 2007.

[5] D. A. Fungaro, M. Bruno, L. C. Grosche. Adsorption and kinetic studies of methylene blue on zeolite synthesized from fly ash, Desalination and Water Treatment, Vol. 2, 231-239, 2009.

[6] D. A. Fungaro, L. C. Grosche, A. S. Pinheiro, J. C. Izidoro, S. I. Borrely. Adsorption of methylene blue from aqueous solution on zeolitic material and the improvement as toxicity removal to living organisms, Orbital, Vol. 2, 235-247, 2010.

[7] D. A. Fungaro, M. Yamaura,T. E. M. Carvalho. Adsorption of anionic dyes from aqueous solution on zeolite from fly ash-iron oxide magnetic nanocomposite, Journal of Atomic and Molecular Sciences, Vol. 2, 305-316, 2011.

[8] R. S. Bowman. Applications of surfactant-modified zeolites to environmental remediation. Review, Microporous Mesoporous Materials, Vol. 6, 43-56, 2003.

[9] G. M. Haggerty, R. S. Bowman. Sorption of chromate and other inorganic anions by organo-zeolite, Environmental Science \& Technology, Vol. 28, 452-458, 1994.

[10] Z. Li, R. S. Bowman. Counterion effects on the sorption of cationic surfactant and chromate on natural clinoptilolite, Environmental Science \& Technology, Vol. 31, 2407-2412, 
1997.

[11] K. Hunger. Industrial dyes: Chemistry, Properties, Applications, Wiley-VCH, Germany, 2003.

[12] A. Stolz. Basic applied aspects in the microbial degradation of azo dyes, Applied Microbiology and Biotechnology, Vol. 56, 68-80, 2001.

[13] V. K. Gupta, Suhas. Application of low-cost adsorbents for dye removal - A review. Journal Environmental Manager, Vol. 90, 2313-2342, 2009.

[14] N. Sharma, D. P. Tiwari, S. K. Singh. Decolourisation of Synthetic Dyes by Agricultural Waste- A Review. International Journal of Scientific \& Engineering Research, Vol. 3, 1-10.

[15] T. Henmi. Increase in cation exchange capacity of coal fly ash by alkali treatment, Clay Science, Vol. 6, 277-282, 1987.

[16] D. A. Fungaro, S. I. Borrely. Síntese e caracterização de zeólita de cinzas de carvão modificada por surfactante catiônico, Cerâmica, Vol. 58, 77-83, 2012.

[17] G. Blanchard, M. Maunaye, G. Martim. Removal of heavy metals from waters by means of natural zeolites, Water Research, Vol. 18, 1501-1507, 1994.

[18] Y. S. Ho, G. McKay Sorption of dye from aqueous solution by peat. Chemical Engineering Journal, Vol. 70, 115-12, 1998.

[19] Y. S. Ho, G. McKay. Pseudo-second order model for sorption processes, Process Biochemistry, Vol. 34, 451-465. 1999.

[20] W. J. Weber, J. C. Morris. Kinetics of adsorption carbon from solutions, Journal Sanitary Engineering Division Proceedings. American Society of Civil Engineers, Vol. 89, 31-60, 1963.

[21] K. Y. Foo, B. H. J. Hammed. Insights into the modeling of adsorption isotherm systems, Chemical Engineering Journal, Vol. 156, 2-10, 2010.

[22] M. C. Ncibi. Applicability of some statistical tools to predict optimum adsorption isotherm after linear and non-linear regression analysis. Journal Hazardous Material, Vol. 153, 207-212, 2008 .

[23] J. Scott, D. Guang, K. Naeramitmarnsuk, M. Thabuot, R. Amal, Zeolite synthesis from coal fly ash for the removal of lead ions from aqueous solution. J. Chem. Technol. Biotechnol., Vol. 77, 63-69, 2001.

[24] D. A. Fungaro, C. P. Magdalena. Adsorption of Reactive Red 198 from aqueous solution by organozeolite from fly ash: Kinetic and Equilibrium studies, International Journal of Chemical and Environmental Engineering Systems, Vol. 3, No. 3,74-83, 2012.

[25] D. A. Fungaro, S. I .Borrely, T. E. M. Carvalho. Surfactant Modified Zeolite from Cyclone Ash as Adsorbent for Removal of Reactive Orange 16 from Aqueous Solution. American Journal of Environmental Protection, Vol. 1, No. 1, $1-9,2013$.

[26] F. Cakicioglu-Ozkan, S. Ulku. The effect of $\mathrm{HCl}$ treatment on water vapor adsorption characteristics of clinoptilolite rich natural zeolite, Langmuir, Vol. 77, 47-53, 2005.

[27] Z. Li, R. S. Bowman. Sorption of perchcholoethylene by surfactant-modified zeolite as controlled by surfactant loading. Environmental Science \& Technology, Vol. 32, 2278-2282, 1998.

[28] H. Guan, E. Bestland, C. Zhu, H. Zhu, D. Albertsdottir, J. Hutson,C .T. Simmons, M. Ginic-Markovic, X. Tao, A. V. J. Ellis, Variation in performance of surfactant loading and resulting nitrate removal among four selected natural zeolites, Journal of Hazard Materials, Vol. 183, 616-621, 2010.

[29] Z. Li. Sorption kineticts of hexadecyltrimethylammonium on natural clinoptilolite, Langmuir, Vol. 15, 6438-6445, 1999.

[30] M. Rozic, D. I. Sipisic, L. Sekovanic, S. Miljanic, L. Curkovic, J. Hrenovic. Sorption phenomena of modification of clinoptilolite tuffs by surfactant cations. Colloid Interface Science, Vol. 331, 295-301, 2009.

[31] J. C. Izidoro, D. A. Fungaro, J. E. Abbott, S. Wang. Synthesis of zeolites $\mathrm{X}$ and A from fly ashes for cadmium and zinc removal from aqueous solutions in single and binary ion systems, Fuel, Vol. 103, 827-834, 2013.

[32] J. C. Izidoro, D. A. Fungaro, S. Wang. Zeolite synthesis from Brazilian coal fly ash for removal of $\mathrm{Zn}^{2+}$ and $\mathrm{Cd}^{2+}$ from water. Advanced Materials Research, Vols. 356-360, 1900-1908, 2012.

[33] S. J. Allen, G. Mckay, K. Y. H. Khader. Intraparticle diffusion of a basic dye during adsorption onto sphagnum peat. Environmental Pollution, Vol.56, 39-50, 1989.

[34] C. H. Giles, T. H. MacEwan, S. N. Nakhwa, D. Smith. Studies in adsorption. Part XI. A system of classification of solution adsorption isotherms, and its use diagnosis of adsorption mechanisms and in measurement of specific surface areas of solids. Journal of the Chemical Society, London. Vol. 111, 3973-3993, 1960.

[35] F. H. Frimmel, L. Huber. Influence of humic substances on the aquatic sorption of heavy metals on defined minerals phases. Environment International, Vol. 22, 507-517, 1996.

[36] Y .Liu. Is the Free Energy Change of Adsorption Correctly Calculated? Journal of Chemical Engineering Data, Vol. 54, 1981-1985, 2009.

[37] Z. Li, I. Anghel, R. S. Bowman. Oxyanion sorption by surfactant-modified zeolite. Journal Dispersion Science Technology, Vol. 19, 843-857, 1998.

[38] S. B. Velegol, B. D. Fleming, S. Biggs, E. J. Wanless, R. D. Tilton. Counterion Effects on Hexadecyltrimethylammonium Surfactant Adsorption and Self-Assembly on Silica, Langmuir, Vol. 16, 2548-2556, 2000.

[39] D. Karadag. Modeling the mechanism, equilibrium and kinetics for the adsorption of Acid Orange 8 onto surfactant-modified clinoptilolite: The application of nonlinear regression analysis. Dyes and Pigment, Vol. 74, 659-664, 2007.

[40] S. K. Ghadiri, R. Nabizadeh, A. H. Mahvi, S. Nasseri, H. Kazemian, A. R. Mesdaghinia, S. Nazmara. Methyl tert-butyl ether adsorption on surfactant modified natural zeolites, Iranian Journal of Environmental Health Science \& Engineering, Vol. 7, 241-252, 2010.

[41] A. Torabian, H. Kazemian, L. Seifi, G. N. Bidhendi, S. K. Ghadiri. Removal of Petroleum Aromatic Hydrocarbons by Surfactant-Modified Natural Zeolite, Clean- Soil, Air, Water, Vol. 38, 77-83, 2010. 